\title{
A Study on the Educators' Basic Quality of Traceless Strengthening Educational Activity
}

\author{
Hong Yang \\ Wuhan Railway Vocational College of Technology, Wuhan, China
}

\begin{abstract}
The educators' basic quality of traceless strengthening educational activity is researched in detail. First, the unqualified educators, the good educators, and the excellent educators defined in detail. Second, the basic quality possessed by the educators is given, and sense of responsibility, organizing ability, administrative skills are defined in detail. Besides, the exact meaning of "traceless" is revealed. Third, the significance of good moral conduct is discussed to get better result in a traceless strengthening educational activity. And, a certain causal relationship in the midst of some quality like sense of responsibility, organizing ability, administrative skills and moral conduct is discussed. After this, that the excellent educators should possess good morality and healthy psychology is discussed. Finally, the basic quality of the good educators and the excellent educators are described more precisely.

Index Terms - Traceless, strengthening education, basic quality, educators, educatees.
\end{abstract}

\section{Introduction}

As we know, if people are not strong enough, there is little possibility for them to serve the country. Therefore, the strengthening education is an important in China's contemporary higher education. The traceless strengthening educational theory and the traceless strengthening educational activity with high efficiency are recently given by the writer, after many strengthening educational theories are researched and a lot of experience of the practice of strengthening educational activity is summed up. In a trackless strengthening educational activity, the educatees are put in a state where they have no idea that they are being educated, when put in tribulation, they may act unexpectedly to go against the implementation and completion of the strengthening educational activity, because the strengthening educational purpose is hidden by a lively activity. So, there is a good strengthening educational effect to the educatees including the young student with reverse psychology in the strengthening educational activities. The educators are superintendents who are in charge of the whole traceless strengthening educational activity, and hence they should have strong power in management. In fact, a good educator should possess not only certain managing ability in a traceless strengthening educational activity, but also they have good quality and morality. Therefore, it is highly necessary to research basic quality and moral conduct of the educators.

\section{Basic Quality of the Educators}

Various traceless strengthening educational activities can not be generalized though they have their own particularity. But their common ground is "traceless". In many cases, the traceless strengthening education indicates the educatees receive educational content and purpose passively and unconsciously. So "traceless" means passive, unconscious, uncertainty and volatility. Sure, sometimes it means risky. Looked at in this light, the educators have to possess some basic quality if the educators want to get a good effect in a traceless strengthening educational activity. Generally speaking, the educators fall broadly into three categories: the unqualified educators, the good educators, and the excellent educators. So called unqualified educator is a failure as a superintendent in the traceless strengthening educational activity. So called good educator is well-qualified for a superintendent in the traceless strengthening educational activity, as regards thinking and capability. So called excellent educator is a pretty good educator. The good educators or the excellent educators are both competent and efficient. But the unqualified educators should are excluded when the educators' basic quality of traceless strengthening educational activity is researched. In fact, the good educators or the excellent educators all must possess some quality like strong sense of responsibility, certain organizing ability, essential administrative skills. First, as the good educators or the excellent educators in a traceless strengthening educational activity, they should have sense of responsibility. So-called sense of responsibility is a sense that the educators must make a conscious effort to fulfill their duties in a traceless strengthening educational activity. The educators are in charge of the whole situation of a traceless strengthening educational activity, and they shoulder the responsibility of regulating and controlling it. So the good educators or the excellent educators must be a good manager. And, a good or excellent manager is based on possessing their own strong sense of responsibility, strong organizational ability, strong administrative skills, good behavior, etc. But, sense of responsibility is the most important in these qualities. Indeed, "traceless" means that the traceless strengthening educational activity has much uncertainty and volatility, and it can be sometimes risky. Therefore, secure job must be pushed into first place in a traceless strengthening educational activity. Safety consciousness is the most important in sense of responsibilities. Of curse, the personal safety is the most important in sense of responsibility, because persons are the most important part in a traceless strengthening educational activity. Therefore, the sense of responsibility is one of the basic qualities of the good educators or the excellent educators, and it is pushed into first place.

Second, as the good educators or the excellent educators, they should have strong organizational ability. So-called 
organizational ability is a capability of integrating the educatees, sources and conditions, in which both what the educators do is work out the best arrangement for carrying out its objective-related tasks, and the educational individuals and the educational resources are brought together for the purpose of attaining the traceless strengthening educational objectives. As the good educators or the excellent educators of a traceless strengthening educational activity, they are good or excellent managers of the whole educational course. Generally speaking, the main organizing work of the educators in a traceless strengthening educational activity includes determining the tasks of the work that will have to be performed, grouping the tasks of the work into some logical framework, and assigning the tasks of the work to the people in the organization. Often, the good or excellent educators can go straight for the jugular when they arrange separate persons or things into a systematic and organic whole in a traceless strengthening educational activity. This is impossibilities if the educators are not good or excellent organizers. Moreover, there are always many unexpected things which are exceedingly troublesome in the organizing work of a traceless strengthening educational activity, and these things are often the important factors causing the psychological pressure of the educators. So the organizing work is often very hard and painstaking work. This means as good or excellent educators in a traceless strengthening educational activity, their organizational ability should be good, and even excellent. That is, good or excellent organizational ability is an essential attribute for the good or excellent educators.

Third, as the good educators or the excellent educators, they should have strong administrative skills. So-called administrative skills are specific ability or concrete wisdom exhibited by the educators trying to manage a traceless strengthening educational activity. Generally speaking, the good educators or the excellent educators in a traceless strengthening educational activity should be outstanding managers. As the outstanding managers, the good educators or the excellent educators should possess three basic skillscontrol skills, teambuilding skills, and drive skills. So-called control skills are the ability and measure that the educators organize and schedule actions of the educatees so it is achieved when expected, and meets established standards. So-called teambuilding skills are the ability and measure that the educators arrange separate educatees into teams through some proper management style in a traceless strengthening educational activity. So-called drive skills are the ability and measure that the educators stimulate the educatees' combativeness finishing their task as effectively as possible. When managing a traceless strengthening educational activity, the educators should pay attention to the following jobs: listening for insights, directing in time, and doing for safety. Actually, it is not easy to possess outstanding administrative skills, because good or excellent administrative skills have to be acquired through practicing constantly, rather than merely learning in theory. Therefore, the good educators or the excellent educators should combine theory with practice so that their administrative skills are improved effectively. The above basic quality, while necessary, is not enough, if a traceless strengthening educational activity not only can go well but also can get a satisfying result.

\section{Moral Conducts of the Educators}

Specifically, the basic quality the excellent educators includes strong sense of responsibility, excellent organizing ability, expert administrative skills and good moral conducts, and healthy psychology, etc. Moral conducts of the educators usually plays a prominent role in order that a traceless strengthening educational activity goes well, and gets a satisfying result. So the excellent educators must have good moral conducts. Meanwhile, their good moral conducts will bring much good in a traceless strengthening educational activity.

First, the good educational effect not only is connected with organizing and monitoring of the educators in a traceless strengthening educational activity but also is linked to behavior and morality of them. In general, it is usually impossible to get the good educational effect in a traceless strengthening educational activity if the educators are not willing to work hard. But then the educators with good moral conducts are willing to work very hard.

Second, sense of responsibility, organizational ability, and administrative skills of the educators have more direct relationship with moral conducts of them. For example, sense of responsibility is based on self-discipline and self-sacrifice, organizational ability is based on self-reliance and selfconfidence, and administrative skills are usually formed on sense of responsibility and organizational ability. In fact, selfreliance, self-discipline, and self-confidence are concrete manifestations of good behavior and good morality.

Third, the educators with good moral conducts let readily the educatees like them, and then their good moral conducts will be emulated more effectively by the educatees in words and deeds. While this happens, this emulation is usually "traceless". Speaking clearly, if the educators can let the educatees strive to improve themselves more efficiently in the strengthening educational activities that make students become stronger in self-reliance, self-discipline, and self-confidence, they should first be a man of self-reliance, self-discipline, and self-confidence. Sometimes, the performance of the educatees are just a soundless echo the performance of the educatees in a traceless strengthening educational activity. This is very important. The educatees who are educated in a traceless strengthen educational activity are interpreted as selfdependent men, and their ability and quality of self-reliance must be formed by themselves in a traceless strengthen educational activity. Furthermore, the educatees are outstanding imitators. Therefore, it is inevitable that they could imitate the educators' mannerism when forming their selfreliant ability and quality in a traceless strengthening educational activity. Usually, the imitating will change silently the educatees' mannerism, and then it eventually triggers their striatum to make some behaviors almost automatic. In other 
words, the educators should first is a man of self-reliance, selfdiscipline, and self-confidence in order to let the educatees get better results in self-reliance, self-discipline and selfconfidence. Therefore, the excellent educators must have good moral conducts in order that a traceless strengthening educational activity goes well and gets a good educational effect more smoothly.

\section{Conclusion}

Today, more and more young students take college diplomas, but more and more young students do not have enough abilities in self-reliance and self-care. It is well known that there is little possibility for you to serve your country if you are not a man of self-reliance. Young people are the pillar of our country. Therefore, the strengthening education is very important at present. Many young students are discontented with traditional strengthening education and its activity, and manifestations of reverse psychology are very outstanding in traditional strengthening educational activities like military training, and morning exercises, so that outcomes are poor in them. For this reason, a traceless strengthening educational activity is given by author. As superintendents of a traceless strengthening educational activity, the educators may encounter all kinds of knotty problems or dangers in a traceless strengthening educational activity, and then they are probably challenged in order to get a traceless strengthening educational activity done well. Therefore, the educators must have certain quality, including good morality or healthy psychology. Indeed, once there is not good morality or healthy psychology; there is not strong sense of responsibility, clear and efficient thinking, or ability of problem solving in high effect. If so, the educators can't be so excellent that they can let themselves perform at their best to get the most satisfying effect in a traceless strengthening educational activity. This means that the excellent educators should have the higher quality than the good educators. All in all, the basic quality of the good educators includes strong sense of responsibility, certain organizing ability, essential administrative skills and good moral conducts, and the basic quality of the excellent educators includes strong sense of responsibility, excellent organizing ability, expert administrative skills, good moral conducts, and healthy psychology, etc.

\section{References}

[1] Shan Ying, The Original Theory of Higher Education. Beijing: Education and Science Press, 2008. (In Chinese)

[2] Sun Shaorong, Introduction to Higher Education Method. Shanghai: East China Normal University Publishing House, 2010. (In Chinese)

[3] Jiamei LU, Psychology and Education - Theory and Practice. Shanghai: Shanghai education Publishing House, 2011. (In Chinese)

[4] Gao Shenying, New Ideas for Effective Teaching - Studies of the Changes in Teaching of the Western Schools since the 1980s. Jinan: Shandong Education Press, 2011. (In Chinese)

[5] Hong YANG, An Exploration of Effect Evaluation Model for Limited Strengthening Education. In: Proceedings of 2012 International Symposium-Educational Research and Educational Technology. Melbourne: ST.PLUM-BLOSSOM PRESS, APR 2012. p335-339(In Australia)

[6] Hong YANG, An Exploration of a New Strengthening Education Model. International Conference on Computer Science and Education, 2012Vo1.5 No.1.

[7] Hong YANG, The Exploration and Research on the Decision Making Process and Organizing Work of the Traceless Strengthening Education of the College Students. In: The Conference on Management Innovation Intelligent Technology and Economic Development. Nanchang: Hong Kong Education and Research Press, July 2012. p198-202(In China) 